\title{
Measuring manufacturing flexibility a resource-elements based approach
}

\author{
N. N. Z. Gindy and S. M. Saad \\ Department of Manufacturing Engineering and Operations \\ Management, University of Nottingham, Nottingham NG7 2RD, \\ England, Tel +44-115-951 4048, Fax +44-115-951 4000 \\ Emailepxsmis@epn1.maneng.nott.ac.uk
}

\begin{abstract}
Flexibility is one of the critical performance measures of manufacturing systems. It describes the system's ability to adapt and be responsive to changing production requirements. This paper deals with some issues relating to manufacturing flexibility and the measures that may be used in its evaluation based upon detailed description of the capabilities of machine tools and machining facilities using generic capability units termed "Resource Elements". Three new measures of manufacturing flexibility are proposed and examples are provided to show how they may be applied.
\end{abstract}

\section{Keywords}

Manufacturing systems flexibility, resource elements

\section{INTRODUCTION}

Some factors influencing the direction of future manufacturing are already apparent: global competitive markets and supply chains; shortened product life cycles; increasing requirements for quality; increasing customisation of products; faster paced advances in increasingly complex technology; rapidly expanding options in materials and processes and increasing skill requirements. In the last few years, time to market, product cost and quality have emerged as the dominant factors which determine manufacturing competitiveness and responsiveness.

The development of appropriate description methods and measures for the various facets and attributes of flexibility of manufacturing systems is an important step towards reaching a good understanding of system flexibility and hence being able to utilise it to improve system performance and responsiveness.

Although many of the issues relating to manufacturing flexibility have been the subject of comprehensive studies in recent literature, manufacturing flexibility still is poorly understood. A variety of different types and facets of flexibility are emphasised by researchers Kumar (1986). As examples, Buzacott (1982) defines flexibility as the essential feature of flexible manufacturing 
systems and the emphasis is put on job flexibility and machine flexibility. Brown et al. (1984) define and describe eight types of flexibility that include: machine, process, product, routing, volume, expansion, operation and production flexibility. Carter (1986) defines flexibility as a collection of properties of a manufacturing system that support changes in production activities or capabilities and discusses how different types of flexibility impact production in different time frames including very short term, short term, medium term and long term. Son and Park (1987) define flexibility as a measure of manufacturing performance which indicates the adaptability of manufacturing systems to changes in the manufacturing environment and consider four different types of flexibility relating to, equipment; Product; process and demand. Sethi and Sethi (1990) define flexibility as adaptability of a system to a wide range of possible environments that may encounter and discuss eleven different types of flexibility which comprise: machine, material handling, operation, process, product, routing, volume, expansion, program, production and market.

In this work the focus is on what can generally be described as "flexibility of machining environments". Definitions for "load " and "routing" flexibility are given and new measures are proposed for their assessment. The proposed measures are based on dividing machining facilities into generic capability units termed "Resource elements" ( $\left.R E^{\prime} s\right)$ which are based upon detailed analysis of the capabilities of the manufacturing environment. The next section introduces briefly the resource element $(R E)$ concept. In section 3 a measure for "machine" flexibility using $R E$ is presented. In sections 4 and 5 "load" and "routing" flexibility and their assessment measures are presented.

\section{RESOURCE ELEMENTS $(R E)$}

Resource Elements are defined as machining facility specific capability units, which capture information relating to the distribution (commonality and uniqueness) of form generating schema among the machine tools included in the machining facility. A Form Generating Schema (FGS) is a technologically meaningful combination of a cutting tool of specific geometry, a set of relative motions between a part and the cutting tool, and the typical levels of technological output (surface finish, tolerances etc) associated with using that combination of tool and relative motions. The available machine tools in a manufacturing system can be described using a set of $R E$ where each $R E$ represents a collection of form generating schema such that the exclusive and the shared capability boundaries between all the available machine tools comprised in a manufacturing facility are uniquely identified. Figure 1 shows a diagrammatic representation of a machining

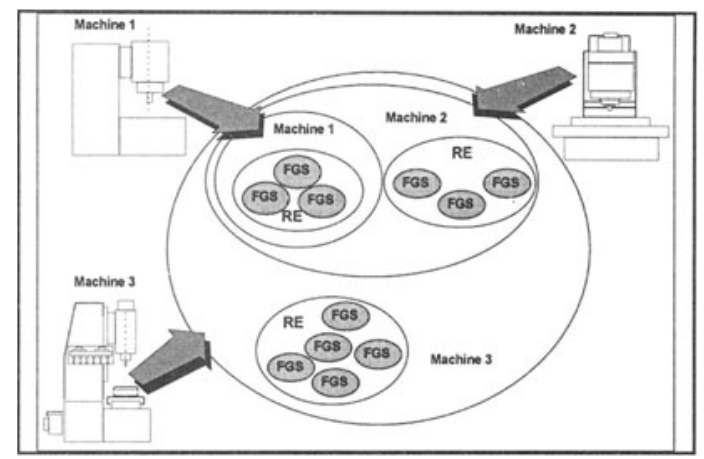

Figure 1 Representation of machining facility using REs. 
facility based on its $R E$ content. Full explanation of the $R E$ concept is beyond the scope of this paper, for more details refer to Gindy et al. (1996).

\section{MACHINE FLEXIBILITY}

Machine flexibility as defined in Sethi and Sethi (1990) relates to the various types of machining operations that a machine tool can perform without requiring a prohibitive effort in switching from one operation to another. The measures proposed by Brill and Mandelbaum (1989) are based upon the relative importance of the operations a machine executes and the efficiencies of machine tools in performing such operations. Son and Park (1987) measure "machine" flexibility in terms of the capability of the machine to add value to raw materials. Das and Nagendra (1993) measure "machine" flexibility as the sum of the efficiencies by which it performs different operations. Brill and Manelbaum (1989) suggest that the efficiency of the machine could be a measure of output quality, throughput, reliability, and maintenance cost.

In a similar treatment to Das and Nagendra's (1993), the efficiency of the machine tools based upon their resource elements can be calculated in terms of its setup and processing time required for component machining. The overall "machine" flexibility in a machining facility is computed as:

$$
\text { Machf }=\frac{1}{n} \sum_{k=1}^{n} \frac{1}{\sum_{j=1}^{m \in R E_{k}} R E_{k j}} \sum_{j=1}^{m \in R E_{k}} E_{R E_{k j}}
$$

where:

$$
\begin{array}{ll}
m & =\text { number of machines, } \\
j & =1,2, \ldots \ldots \ldots . . m \\
n & =\text { number of different resource elements, } \\
k & =1,2, \ldots \ldots \ldots . ., \\
R E_{k j} & =\text { resource element } k \text { on machine } j, \\
E_{R E k, j} & =\text { efficiency of resource element } k \text { on machine } j, \\
P_{R E k j} & =\text { processing time required by resource element } k \text { on machine } j, \\
S_{R E k, j} & =\text { set up time required by resource element } k \text { on machine } j,
\end{array}
$$

The efficiency of $R E_{k_{j}}$ to perform the required machining becomes:

$$
E_{R E_{t j}}=\frac{\left(S_{R E_{k}}\right)_{\min }}{S_{R E_{k j}}} \times \frac{\left(P_{R E_{k}}\right)_{\min }}{P_{R E_{k j}}}
$$

An illustrate example is shown in Table 1. Based on conducting an analysis of the capabilities of machine tools contained in the facility 22 different resource elements were identified and the efficiency matrix defined (null indicates that the resource is not available on a machine tool). For instance, $R E 22$ is available on machine numbers 4 and 9 and the efficiency when utilising this resource to perform a required machining task is assessed as $100 \%$ and $90 \%$ respectively. 
Table 1 Example efficiency matrix for machining tools centres and its resource elements

\begin{tabular}{|c|c|c|c|c|c|c|c|c|c|c|c|c|c|c|}
\hline & $M / C$ & $M / C$ & $M / C$ & $M / C$ & $M / C$ & $M / C$ & $M / C$ & $M / C$ & $M / C$ & $M / C$ & $M / C$ & $M / C$ & $M / C$ & $M / C$ \\
\hline & 1 & 2 & 3 & 4 & 5 & 6 & 7 & 8 & 9 & 10 & 11 & 12 & 13 & 14 \\
\hline$R E 1$ & 0 & 0 & 0 & 0.8 & 0.9 & 0.9 & 0 & 0 & 0.8 & 0 & 0 & 1 & 0.7 & 0 \\
\hline$R E 2$ & 0 & 0.9 & 0.8 & 1 & 0.7 & 0.7 & 0 & 0 & 0 & 0.8 & 0.9 & 1 & 0.8 & 0 \\
\hline$R E 3$ & 0.9 & 0.8 & 0.7 & 1 & 0 & 0 & 0 & 0 & 0 & 0.8 & 0.9 & 1 & 0.7 & 0 \\
\hline RE4 & 0 & 0 & 0 & 0 & 0.8 & 0.9 & 0 & 0 & 0 & 0 & 0 & 0 & 1 & 0 \\
\hline RE5 & 0 & 0 & 0 & 0 & 0 & 0 & 1 & 0 & 0 & 0 & 0 & 0 & 0 & 0 \\
\hline RE6 & 0 & 0 & 0 & 0 & 0 & 0 & 0 & 1 & 0 & 0 & 0 & 0 & 0 & 0 \\
\hline .......... & .. & .. & .. & .. &.. &.. &.. &.. &.. &.. &.. &.. &.. & .. \\
\hline$R E 22$ & 0 & 0 & 0 & 1 & 0 & 0 & 0 & 0 & 0.9 & 0 & 0 & 0 & 0 & 0 \\
\hline
\end{tabular}

The overall efficiency of an $R E$, in performing the required task, is calculated as the average of the efficiency of all the machine tools in which the $R E$ appears. A summary of $R E$ efficiencies is shown in Table 2.

Substitution of the data shown in Table 2 in equation 1 gives the machine tool efficiency as Machf $=89.9 \%$.

Table 2 The efficiency matrix in terms of $R E s$

\begin{tabular}{|c|c|c|c|c|c|c|c|c|c|c|c|}
\hline & $R E 1$ & $R E 2$ & $R E 3$ & RE4 & RE5 & RE6 & RE7 & $R E 8$ & $R E 9$ & RE10 & RE11 \\
\hline Ave. Efficiency & 0.85 & 0.84 & 0.85 & 0.9 & 1 & 1 & 0.82 & 0.88 & 1 & 0.9 & 0.85 \\
\hline \multirow[t]{4}{*}{ Number of $R E_{k}$} & 6 & 9 & 8 & 3 & 1 & 1 & 5 & 4 & 1 & 3 & 4 \\
\hline & $R E 12$ & RE13 & $R E 14$ & $R E 15$ & $R E 16$ & RE17 & RE18 & $R E 19$ & $R E 20$ & RE2I & $R E 22$ \\
\hline & 0.82 & 1 & 0.83 & 0.85 & 0.9 & 1 & 0.95 & 0.83 & 0.9 & 0.87 & 0.9 \\
\hline & 4 & 1 & 4 & 2 & 2 & 1 & 2 & 3 & 2 & 3 & 2 \\
\hline
\end{tabular}

The use of resource elements to describe the capabilities of machine tools and machining facilities allows the selection, loading and scheduling of machining resources to be carried out based on pre-knowledge regarding the total number of $R E$ 's in the system as well as the number of repeated resources elements contained in the machining facility. This is a much higher level of detail than what is available when a machining facility is described based on "whole" machine tools. The routing and loading flexibility of a manufacturing facility is heavily dependent on the number of repeated resources and the similarity and uniqueness of its machining resources.

\section{LOAD FLEXIBILITY}

"Load" flexibility relates to the variation in the distribution machining tasks amongst the resources available in a manufacturing facility. A manufacturing facility which has a smooth and even load 
distribution is more flexible in accepting new jobs into the system much more easily than a manufacturing environment in which resources are unevenly loaded or bottle-necked $(100 \%$ utilisation). Load flexibility therefore, can have a significant impact on the responsiveness of manufacturing systems in terms of its ability to cope with changes in production volumes and variety of the components it manufactures.

Load flexibility is measured by a relationship between the availability of an $R E_{k}$, required for a machining task, and the variation in the utilisation of machine tools in which $R E_{k}$ is available. Machine utilisation is defined as the proportion of time that a machine is busy doing a useful task [Saad (1994)]. The variation in machine utilisation is measured utilising the standard deviation of machine utilisation from its mean value. Load flexibility is measured as:

$$
\text { Loadf }=\left(1-\frac{\sum_{k=1}^{n} U_{R E_{k}}}{n}\right)\left(1-\sigma_{U_{j}}\right)
$$

where:

$$
\begin{array}{llc}
U_{R E k} & =\text { utilisation of } R E_{k} . & (k=1,2, \ldots \ldots \ldots . . n) \\
\sigma_{U j} & =\text { standard deviation of machine utilisation. } & (j=1,2, \ldots \ldots \ldots . . m)
\end{array}
$$

Load flexibility can be illustrated as follows: Consider the group of machining centres shown in Table 1 and the machine and $R E$ utilisations shown in Tables 3 and 4 respectively.

Table 3 Machine utilisation

\begin{tabular}{lllllllllllllll}
\hline$M / C$ & 1 & 2 & 3 & 4 & 5 & 6 & 7 & 8 & 9 & 10 & 11 & 12 & 13 & 14 \\
\hline$U_{j}$ & 30.0 & 18.9 & 32.9 & 46.6 & 24.6 & 61.3 & 17.6 & 69.9 & 23.9 & 38.9 & 44.6 & 82.4 & 38.7 & 35.6 \\
\hline
\end{tabular}

Table 4 Resource element utilisation

\begin{tabular}{llllllllllll}
\hline & $R E 1$ & $R E 2$ & $R E 3$ & $R E 4$ & $R E 5$ & $R E 6$ & $R E 7$ & $R E 8$ & $R E 9$ & $R E 10$ & $R E 11$ \\
\hline$U_{R E}$ & 50.0 & 43.2 & 37.9 & 41.5 & 17.6 & 69.9 & 50.7 & 53.1 & 0.0 & 57.9 & 51.6 \\
\hline
\end{tabular}

\begin{tabular}{llllllllllll}
\hline$R E 12$ & $R E 13$ & $R E 14$ & $R E 15$ & $R E 16$ & $R E 17$ & $R E 18$ & $R E 19$ & $R E 20$ & $R E 21$ & $R E 22$ \\
\hline 44.0 & 82.4 & 31.9 & 50.0 & 56.3 & 53.5 & 49.1 & 58.2 & 57.3 & 47.2 & 43.5 \\
\hline
\end{tabular}

Based on Tables 3 and 4 and equation 2, load flexibility can be computed as:

$$
\begin{aligned}
\text { Loadf } & =(1-0.4758)(1-0.1856) \\
& =42.69 \%
\end{aligned}
$$

Examination of the above figures provides insight into the proposed measure. The following conclusions can be drawn:

1. Loadf is maximum when $R E_{k}$ utilisation and standard deviation of machine utilisation are zero.

2. Loadf is minimum when either $R E_{k}$ fully utilised (i.e. $100 \%$ ) or standard deviation of 
machine utilisation is unity.

3. Loadf increases with increasing the number of resources available in the system or when the system resources are evenly loaded.

Figure 2 shows the relationship between the load flexibility and the variation in machine utilisation $\left(1-\sigma_{U j}\right)$. As can be seen the smaller the variation in machine utilisation the higher the value of load flexibility:

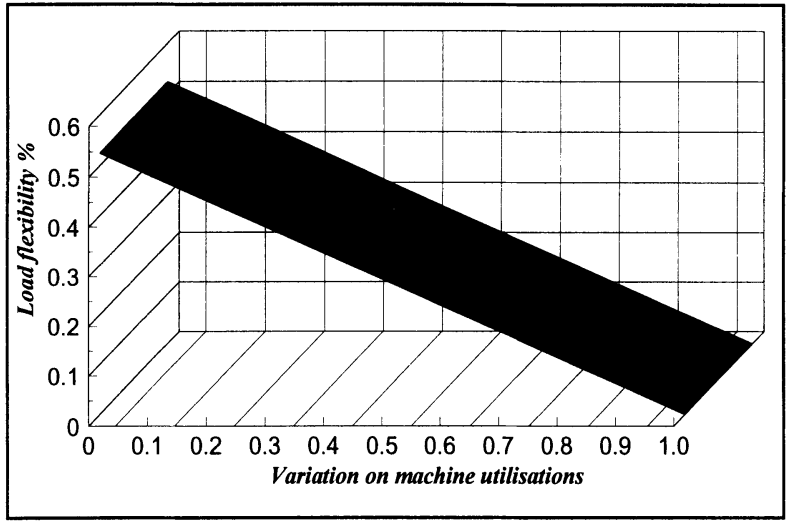

Figure 2 Variation in machine utilisation versus flexibility ( at $R E_{k}$ utilisation $=0.4758$ ).

\section{ROUTING FLEXIBILITY}

Routing flexibility of a manufacturing system as defined in Sethi and Sethi (1990) is the ability of a manufacturing system to produce a part by alternate routes utilising the available system resources. Similar definition has been used by Das and Nagendra (1993), Falkner (1986), Buzacott (1982) and Carter (1986). Other authors such as Buzacott (1982), Browne et al. (1984) and Upton and Barash (1988) emphasize the ability of the system to reroute parts in case of machine breakdown. Alternate routes as mentioned in Sethi and Sethi (1990) may use different machines, different operations or different operation sequences.

In this work routing flexibility is considered to depend not only on the number of routes available to produce a product, but also on an assessment of the availability of each alternate route and its efficiency to producing a product [similar to Zahran et al. (1990)]. Routing flexibility of a manufacturing system to produce a certain number of different products is given as:

$$
\text { Routf }=\frac{1}{D} \sum_{d=1}^{D} \frac{1}{t_{d}} \sum_{i=1}^{t_{i d}^{k}} \frac{1}{\sum_{j=1}^{m \in R E_{k}} R E_{k j}} \sum_{j=1}^{m \in R E_{k}} E_{R E_{k j}}\left(1-U_{R E_{K}}\right)
$$

where:

$$
\begin{array}{ll}
D & =\text { number of different products, } \\
d & =1,2, \ldots \ldots \ldots \ldots \ldots \ldots \ldots ., D \\
t_{d} & =\text { number of operations required for product } d, \\
t_{i d}{ }^{k} & =\text { operation } i \text { for product } d \text { using resource element } k
\end{array}
$$


To illustrate routing flexibility, equation 3 is applied to the data shown in Tables 1 and 5 to manufacture three different products $(D=3)$ where: the first product requires resource elements number 1 and 2 , second product needs resource elements number 3 and 4 , and third product needs resource elements number 5 and 6 . Routing flexibility is calculated as $51.4 \%$.

Table 5 Resource element availabilities

\begin{tabular}{lcccccc}
\hline & $R E 1$ & $R E 2$ & $R E 3$ & $R E 4$ & $R E 5$ & $R E 6$ \\
\hline$U_{R E} \%$ & 0.50 & 0.432 & 0.379 & 0.415 & 0.176 & 0.699 \\
$1-U_{R E}$ & 0.50 & 0.568 & 0.621 & 0.585 & 0.824 & 0.301 \\
\hline
\end{tabular}

From equation 3, it can be seen that the number of repeated resource elements, the availability of resources and the efficiency of the machine tool in carrying out the required operations are all factors that will influence routing flexibility in a manufacturing system.

\section{CONCLUSIONS}

Three new measures for different facets of manufacturing flexibility are proposed in this paper: "machine flexibility", "load flexibility" and "routing flexibility. As mentioned by Mandelbaum and Buzacott (1986)"the merit of flexibility is not a measure of flexibility itself but a consequence of it". The merits of the first measure (machine flexibility) lies in its ability to examine the flexibility of a manufacturing facility at the resource element level and therefore provides a much greater level of detail in assessing the flexibility of the available manufacturing resources. The second measure (load flexibility) provides a good indicator regarding system responsiveness in terms of its ability to cope with changes in product volume or variety. The value of the third measure (routing flexibility) lies in its ability to assess the gain that can be achieved by following the various routes that may be available for component processing also the system's ability to cope with disturbances (e.g. machine breakdowns).

The proposed measures are based on a new concept for describing the capabilities of machine tools and machining facilities using generic capability units termed "Resource elements". $R E^{\prime} s$ allows the processing requirements of components, the capabilities of machine tools and machining facilities to be described at a greater level of detail, i.e. at less than a "whole" machine basis, than the conventional machine-based representations. This level of detail helps greatly in providing appropriate matching between components processing requirements and system capabilities well as providing detailed assessment of system flexibility and performance.

\section{REFERENCES}

Brill, P. H., and Mandelbaum, M., 1989, On Measures of Flexibility in Manufacturing Systems. International Journal of Production Research, 27(5), 747-756.

Brown J., Dubois D., Rathmill K., Sethi S. P., and Stecke K. E. (1984) "Classification of Flexible Manufacturing Systems". The FMS Magazine (April 1984), 114-117.

Buzacott J. A. (1982) " The Fundamentals of Flexibility in Manufacturing". Proceedings of the First Int. Conference, Elsevier, North Holland, Amsterdam, (20-22 October), 13-22. 
Carter M. F (1986) "Designing Flexibility Into Automated Manufacturing Systems". Proceedings of the Second ORSA/TIMS Conference on Flexible Manufacturing Systems: Operations Research Models and Applications, edited by K. E. Stecke and R. Suri Elsevier Science Publishers B.V., Amsterdam, 107-118.

Das S. K. and Nagendra P. (1993) "Investigation into the Impact of Flexibility on Manufacturing Performance". International Journal of Production Research, 31(10). 2337-2354.

Falkner, C. H., 1986, Flexibility in manufacturing plants, Proceedings of the Second ORSA/TIMS Conference on Flexible Manufacturing Systems: Operations Research Models and Applications, edited by K. E. Stecke and R. Suri Elsevier Science Publishers B.V., Amsterdam, 95-106.

Gindy N. N. Z., Ratchev T. M., and Case K. (1995) "Component Grouping for Cell Formation Using Resource Elements. International Journal of Production Research, 34(3) $729-759$.

Kumar V. (1986) "On Measurement of Flexibility in Flexible Manufacturing Systems: An Information-Theoretic Approach". Proc. of the Second ORSA/TIMS Conf. on Flexible Manufacturing Systems: Operations Research Models and Applications, edited by K. E. Stecke and R. Suri Elsevier Science Publishers B.V., Amsterdam, 131-143.

Mandelbaum, M., and Buzacott, J. A., 1986, Flexibility and its used: A formal decision process and manufacturing view. Proceedings of the Second ORSA/TIMS Conference on Flexible Manufacturing Systems: Operations Research Models and Applications, edited by K. E. Stecke and R. Suri Elsevier Science Publishers B.V., Amsterdam, 119-129.

Mandelbaum, M., and Brill, P. H., 1989 "Examples of Measurement of Flexibility and Adaptivity in Manufacturing Systems". Journal of Opt Res., 40, No.6, PP.603-609.

Saad, S. M., 1994, Design and analysis of a flexible hybrid assembly system. PhD thesis, Department of Manufacturing Engineering and Operations Management, University of Nottingham, England.

Sethi A. K, and Sethi S. P. (1990) "Flexibility in Manufacturing A Survey". The international Journal of Flexible Manufacturing Systems, 2, 289-328.

Son Y. K., and Park C. S. (1987) "Economic Measure of Productivity, Quality and Flexibility in Advanced Manufacturing Systems". Journal of Manufacturing Systems, 6(3), 193-207.

Upton, D. M., and Barash, M. M., 1988, A grammatical approach to routing flexibility in large manufacturing systems. Journal of Manufacturing Systems, 7, 209-221.

Zahran, I. M., Elmaghraby, A. S., and Shalaby M. A., 1990, Evaluaion of flexibility in manufacturing systems, IEEE International conference on systems, MAN, and Cybernetics, Nov. 4-7, Los Angeles, CA, USA.

\section{BIOGRAPHIES}

Nabil Gindy, BSc, MSc, $\mathrm{PhD}$, is Professor of Advanced Manufacturing Technology and leads the responsive manufacturing group at the University of Nottingham, UK. His research interests include machining and tooling technology, feature-based $\mathrm{CAD} / \mathrm{CAM}$ systems, generative process planning, integrated planning and scheduling systems, CNC part programming and the design and configuration of manufacturing systems.

Sameh Saad, BSc, MSc, $\mathrm{PhD}$, is research fellow at the University of Nottingham, UK. His main research interests include Design and analysis of manufacturing systems, manufacturing systems flexibility, integration of process planning and scheduling and virtual manufacturing. 